\title{
A Critique on the Limitations of the $\mathrm{T}$ and $\mathrm{B}$ Cell Theory
}

\author{
By \\ KazUhiko AWAYA \\ Department of Anatomy, Yamaguchi University School of \\ Medicine, Ube, Yamaguchi-ken 755, Japan \\ -Received for Publication, December 25, 1981-
}

Key words: Lymphocyte, $\mathrm{T}$ and $\mathrm{B}$ cell, Phylogeny of immunity, Paleo- and neoimmunity, Macrophage.

Between 1960 and 1962 new findings were reported that had far reaching effects on immunology. In 1960 Nowell announced that the lymphocyte, which had been viewed until that time as a terminal indivisible cell, could rejuvenate and divide when cultured with phytohaemagglutinin.

At about that same time, the present writer observed mitoses of lymphocytes in circulating blood of rabbits and rats injected ovalbumin and pointed out that it was possible that the lymphocyte divided in circulating blood. At that time, discussion on small lymphocytes dividing was something of a heresy in academic communites of Japan, and the writer withheld publication of his findings. $\mathrm{He}$ did, however, present an outline of his ideas in a lecture given at the Nineteenth Medical Conference of the Yamaguchi Medical School on June, 25, 1961 (Awaya et al. 1961). The findings were published later in the form of a brief report (Awaya et al. 1966), and are reexamined in light of extremely important subsequent developments.

Mori and Senda (1963) independently demonstrated blast-transformation of human peripheral blood lymphocytes in mixed culture. Because of the almost simultaneous discovery of lymphocyte rejuvenation and mitosis by different groups, a new theory of lymphocytes developed with astosishing rapidity. These developments did not fail to make a profound impact on the writer.

In 1962 another finding of immense importance was made public. This was the $T$ and $B$ cell theory, which is the main subject of the present paper. The $T$ stands for the thymus, and the $B$ stands for the bursa of Fabricius. Warner and his colleagues at the Walter \& Eliza Hall Institute of Medical Research in Australia were the first to point out that the lymphocyte population contained both T-type and B-type cells (Szenberg and Warner 1962, Warner and Szenberg 1962, Warner, Szenberg and Burnet 1962). They prevented lymphoid tissue development in the bursa of Fabricius of chicken by injecting testosterone proprionate in ovo, and the immunological response of these "bursaless" chicken was studied using different types of antigenic challenge at two to three months after hatching. There was no antibody production after challenge with the usual antigens, such as bovine serum albumin and human gamma globulin, but the chicken showed a normal rejection reaction to skin homo- 
graft and normal graft versus host (GVH) reactions on chorioallantoic membrane. Moreover, as most chickens were endowed with a normal thymus, it was concluded that there were two lymphocyte populations: bursal lymphocytes charged with the production of antibodies and thymic lymphocytes associated with transplantation immunity.

In 1961, Miller demonstrated that removal of the thymus from mice within 24 hours of birth resulted in: a reduced rate of growth, an increase in animal deaths from a "wasting syndrome", reduced numbers of lymphocytes in blood and lymphatic tissues, and a greatly reduced capacity to reject skin homografts. This was also a discovery of major importance, clarifying the immunological function of thymic lymphocytes. In this way, new avenues of enquiry were opened up, and the $\mathrm{T}$ and $\mathrm{B}$ cell theory became well established. According to Burnet (1976), it seems that the use of the letters $T$ and $\mathrm{B}$ grew out of a paper Warner gave in 1962 at the Minneapolis meeting on immunobiology of the thymus.

One thing that deserves attention, however, in the research of Warner and Szenberg is that their chickens without bursa, despite the presence of an intact thymus, failed to react to challenges of tuberculin or vaccinia virus (Warner et al. 1962). This reaction falls into the category of the so-called delayed hypersensitvity response. At the present time, the delayed response is regarded as a characteristic reaction of $T$ cells. The fact that this reaction did not occur is rather difficult to explain for proponents of $\mathrm{T}$ cell theory. Contemporary investigators on these matters would probably attempt to explain away the difficulties produced by this observation by citing the lack of "cooperative" between $T$ and $B$ cells. Is this, however, a satisfactory explanation?
It will be obvious from what has already been said that the $T$ and $B$ cell theory has been developed on the basis of experiments with chickens and mice. This significant point needs to be remembered. It is my belief that great caution is necessary in applying the theory to other species. In this connection, attention is drawn to the experimental results of Morris and his coworkers at the John Curtin School of Medical Resarch of Australian National University (Cole and Morris, 1971 a, b, c, d). Cole and Morris surgically removed the thymus from the unborn sheep foetus at 60 to 90 days of post-conception. Foetuses thymectomized in utero were born normal lambs, did not show signs of wasting, and grew up normally. They were capable of mounting a normal immune response to Swine influenza virus, Salmonella muenchen organisms, and chicken red blood cells. The thymectomized lambs were capable of rejecting grafts of allogeneic skin as vigorously as normal lambs, and the cellular reactions were histologically the same as the controls. They were able to mount an immediate hypersensitivity response to ferritin, although the delayed type of hypersensitivity response to tuberculin was severely reduced. Of these responses, skin allogaft rejection and delayed hypersensitivity reaction are thought to require the presence of $T$ cells from results on neonatal thymectomy in mice. Therefore, the findings on sheep suggest that it is not possible to apply, without modification, concepts about $T$ cells in mice directly to another species.

In phylogeny research on the immune response by the writer and others, many contradictions appear in $\mathrm{T}$ and $\mathrm{B}$ cell theory. At the present time the hagfish, the most primitive vertebrate, is believed not to be endowed with a thymus. Yet lymphocytes exist in this creature (Figs. 
1-4, Tomonaga et al. 1973). Hildemann and his cowokers showed that one species of hagfish (Eptatretus stoutii) responded specifically to certain immunogens and rejected allografts under appropriate conditions (Hildemann and Thoenes 1969, Thoenes and Hildemann 1970, Linthium and Hildemann 1970).

The present writer also found that another species of hagfish (Eptatretus burgeri) had a normal capacity to reject skin allograft (Awaya et al. 1975). In this work epidermo-dermal grafts were implanted subcutaneously in the dorsal region of the hagfish. The method was suitable for assessing graft rejection. All grafts were examined histologically 7 days after grafting. Autograft controls on animals bearing allografts allowed convenient comparisons. The hagfish were fully capable of rejecting allografts of skin, but autografts were never destroyed (Figs. 5-6). The results are summarized in Table 1. The lymphocytes of this fish cannot be described as $T$ cells, but allograft immunity appears well-established in the absence of thymus.

In the lamprey, on the other hand, the lymphocyte accumulation is found within

Table 1. Fate of autogeneic and allogeneic skin grafts on hagfish seven days after grafting*

\begin{tabular}{|c|c|c|}
\hline \multirow{2}{*}{ Hagfish code } & \multicolumn{2}{|c|}{$\begin{array}{l}\text { Response in the } \\
\text { Epidermal layer }\end{array}$} \\
\hline & Autograft & Allograft \\
\hline 63 & Intact & Destroyed \\
\hline 64 & $\begin{array}{c}\text { Partially } \\
\text { intact }\end{array}$ & $\begin{array}{c}\text { Partially } \\
\text { intact }\end{array}$ \\
\hline 65 & Intact & Destroyed \\
\hline 66 & Intact & Destroyed \\
\hline 67 & Intact & Destroyed \\
\hline
\end{tabular}

* Histologic criteria were determined by responses in the epidermal layer of the test grafts. Autografts were implanted on hagfish bearing allograft. or just beneath the epithelium of the pharyngeal gutter between the second to fifth pharyngeal pouches. This structure is considered to represent the primitive thymus (Good et al. 1966). The writer also found the same structure associated with the pharyngeal epithelia in the lamprey, Lampetra reissneri (Awaya et al. 1969, Awaya 1977). Fig. 7 shows a transmission electron micrograph of this primitive thymus. Thus, $\mathrm{T}$ cell type lymphocytes may phylogenetically first appear in the lamprey of the class Agnatha.

Furthermore, no vertebrate apart from birds is known to have a lymphatic organ corresponding to the bursa of Fabricius. Thus, in a strict sense the term B cell cannot be applied to creatures other than birds. In recent years, for convenience many investigators have expanded the conception of $B$ cells to bone marrow lymphocytes. However, it has been demonstrated that the bone marrow as a phylogenic hematopoietic tissue first becomes differentiated in Anura and is absent in lower vertebrates ranging from the hagfish to the urodeles of amphibians (Osogoe, 1953). Nevertheless, the production of $\operatorname{IgM}$ is reported at even the level of the hagfish (Thoenes and Hildemann 1970). This observation leads inexorably to the conclusion that antibody-forming cells exist at an evolutional level as early as this fish. These early cells, however, are neither bursal lymphocytes nor thymic lymphocytes. Accordingly, in this case, the term B cells cannot be applied. Therefore, the $T$ and $B$ cell theory contains some phylogenic contradictions.

A similar inconsistency is evident in the histogenesis of human lymphatic organs. The general view is that in man stem cells originating from the yolk sac in the embryo or from the bone marrow during postnatal life, enter the thymic primordium and differentiate there into 
T lymphocytes, which then migrate to lymphatic organs, such as the lymph nodes and spleen. Moreover, another kind of stem cell from the bone marrow directly enters the lymph nodes and spleen, without passing through the thymus, becoming B type lymphocytes (antibody-producing cells). This interpretation is an attempt to directly apply to man the view derived from experiments on mice that $T$ and $B$ cells originate either in the thymus or in the bone marrow. This is, however, unlikely in man. In humans it is in the eighth postconception week that lymphocytes are first observed in the primordium of the lymph nodes. At this time, hematopoiesis does not occur at any bone marrow site, and the thymic primordium is composed of only epithelial reticular cells and lymphocytes are not observed there (Table 2). It cannot be claimed, therefore, that lymphocytes seen in the early developmental stages of the human lymph nodes originate either in the bone marrow or in the thymus. Thus, in humans the $\mathrm{T}$ and $\mathrm{B}$ cell theory leaves many questions unanswered.

Moreover, it was said until recently that scanning electron micrographs revealed that the surfaces of $T$ cells were smooth, whereas the surfaces of B cells were rough, being covered with abundant microvilli. The reports by Polliak et al. (1973) and Lin et al. (1973) promoted this view. Our results, however, demonstrated that lymphocytes from both the thymus and bursa of Fabricius of chickens had a smooth (non-microvillous) plasma membrane under scanning electron microscopy (Awaya and Yamaguchi 1975). This is in accordance with the findings of Holbrook et al. (1974). In addition, there were no essential differences in the binding of Concanavalin A to surface membranes of thymic and bursal lymphocytes (Yamaguchi and Awaya 1976). Based upon these observations, the writer has pointed out that it is in fact impossible to distinguish between the $\mathrm{T}$ and $\mathrm{B}$ cells on the basis of the surface morphology (Awaya 1977). Recent trends indicate that this view. is gradually gaining approval.

Both the phytohaemagglutinin (PHA) response and sheep red blood cell (SRBC) rosette formation have been regarded as $T$ cell markers of human peripheral blood lymphocytes. In clinical medicine there have been numerous attempts in recent years to infer $T$ lymphocyte activity using these tests. However, in our experience when both of these measures were examined simultaneously on the same material, the two values often differed. For example, in many patients with liver

Table 2. Embryonal age of the first appearance of lymphocytes in hematopoietic tissues of chicken, mouse and man*

\begin{tabular}{lccccc} 
& Thymus & Bone marrow & Lymph nodes & $\begin{array}{c}\text { Bursa of } \\
\text { Fabricius }\end{array}$ & Liver \\
\hline Chicken & 9 days & & & 13 days & 16.5 days \\
Mouse & 12 days & 17 days & 15 days & & \\
Man & 11 weeks & 12 weeks & 8 weeks & & \\
\hline
\end{tabular}

* Data are cited from following sources.

Chicken: Nomura et al. 1968, Nomura 1973.

Mouse : Kojima and Sakuma 1977, unpublished data of the author.

Man : Matsumura 1967, Kojima and Sakuma 1977. 
disease the E-rosette lymphocyte count was high whereas the PHA lymphocyte count was low (Awaya et al. 1975). This suggests that some qualifications are required in grouping these two types of lymphocytes together under the collective term of $T$ cells and in the evaluation of their function.

To medical researchers concerned with the contemporary $\mathrm{T}$ and $\mathrm{B}$ cell theory great interest has been shown in attempts to distinguish between the two types of lymphocytes by using surface antigens and receptors. Numerous methods of detection have been devised especially on $T$ cells, using surface structural differences as markers. In this way, $\mathrm{T}$ cells have come to be divided into several subsets. In the case of mice, the basis of detection is fairly clear and accurate. In the case of humans, the theoretical basis for these methods is by no means clear. However, some researchers have been attempting to classify human $\mathrm{T}$ and $\mathrm{B}$ cells into a scale extending from normal lymphocytes on one hand to neoplastic lymphoid cells on the other. This may, in its own way, be an exercise of considerable academic value.

It does, however, give rise to several problems. In the first place, viewed even from the technical standpoint, it is clear that unless the methods of identification are reliably consistent and unless there is evidence that the marker is specific to only $T$ cells, the results from the exercise will simply invite confusion. For example, in this connection, there is some basis for concern about the common use of anti-T lymphocyte serum for the detection of $\mathrm{T}$ cell specific antigens. There is concern theoretically, for example, on the identification of surface Ig of $\mathrm{T}$ cells (Marchalonis and Cone 1973, Anderson and Grey 1974). Even in the case of mice, it cannot now be said that the crucial question of whether surface $\mathrm{Ig}$ is actually synthesized by $T$ cells or whether it is the results of $T$ cells passively accepting the Ig synthesized by $\mathrm{B}$ cells has been satisfactorily solved. The problem is even further from a solution in the case of man. Given these unsolved problems, is it justifiable to classify lymphocytes on the basis of surface markers? It is, moreover, necessary to recall here that as far as the question of the origin of lymphocytes is concerned, the $\mathrm{T}$ and $\mathrm{B}$ cell theory contains not a few illogical elements.

There has been a tendency in contemporary immunology to regard the $\mathrm{T}$ and $B$ cell findings as a doctrine of central importance and not as a theory. Yet there are, as I have suggested above, many aspects of this theory that need careful scrutiny. The writer believes that in recent years, young researchers have been inclined to accept this theory far too uncritically. Young people entering this area of research for the first time come with almost a conviction that the lymphocyte population does, in facts, contain both $\mathrm{T}$ and $\mathrm{B}$ cells. They then proceed to interpret the results of their own experiments on the basis of this conviction. When their results do not conform with the framework they attempt to rationalize their results by simply expanding the categories of $\mathrm{T}$ cells to $\mathrm{T}_{1}$, $\mathrm{T}_{2}, \mathrm{~T}_{3}, \mathrm{~T}_{4}$, etc.

Moreover, the influence of this theory has penetrated into the clinical sciences. Clinical specialists attempt to use it to explain data on their patients. Yet as stated earlier, research at the present time with human lymphocytes is modeled on the mouse and other laboratory animals, and it is quite dangerous to apply the results on laboratory animals directly to humans.

It is, nevertheless, convenient to think 
of lymphocytes as being divided into $T$ and $B$ cells, and it is to be expected that this tendency will continue for some time. Yet even so, it is to be hoped that caution will prevail in interpreting the research and clinical data. A hypothesis that may be useful for people with extraordinary insight in research may sometimes be hazardous for beginners in the field. It could perhaps be said that the most desirable course for researchers in the field of lymphocytes is to conduct more experiments and not to interpret their results only on the basis of a facile application of the $\mathrm{T}$ and $\mathrm{B}$ cell theory.

In discussing lymphocytes in contemporary immunology, mention should be made of the importance of the macrophage. The writer would like to end this critique by proposing some new immunological terms. These terms are "paleoimmunity" and "neoimmunity" ("old immunity" and "new immunity"). These terms are based upon "paleocortex" and "neocortex" and have nuances indicating phylogenic involvement. Paleoimmunity prevails at the level of invertebrates. It is from a cytological standpoint a macrophage-type immunity. In this type of immunity, self and non-self elements are identified and non-self elements are eliminated through the phagocytic activity of macrophages. However, this ability is non-specific and lacks so-called immunological memory. Neo-immunity appears primarily in vertebrates above the class Agnatha. It is essentially a lymphocytetype immunity. In this system, antibodies are formed against non-self elements and immunological memory comes into existence. Moreover, since the neoimmunity theoretically evolved on the basis of paleoimmunity, the role of the macrophage is basic and not inferior to that of the lymphocyte. In the past the macroahage has existed in the shadow of the glitter- ing theory on lymphocytes. However today, partly as a result of morphological studies with scanning electron microscopy, and partly because of the introduction of the conception of the mononuclear phagocyte system (MPS), a radical change of outlook has become evident. Detailed information of this subjects will be described elsewhere.

In principio erat macrophagocytus; deinde erat lymphocytus.

\section{Acknowledgement}

This research was supported in part by the Grant-in-Aid for Scientific Research B (No. 00448033) and the Grant-in-Aid for Co-operative Research A (No. 137003) from the Ministry of Education, Science and Culture of Japan.

\section{References}

1) Anderson, C.L. and Grey, H.M.: Receptors for aggregated IgG on mouse lymphocytes. Their presence on thymocytes, thymus-derived, and bone marrow-derived lymphocytes. J. Exp. Med., 139: 1175-1188, 1974.

2) Awaya, K.: Phylogeny of lymphocytes. In : Ebashi, S., Yamada, E. and Oda, T., ed. The Cell. Dynamic Function and Fine Structure (Taisha, Suppl.), pp. 2079-2088, Nakayama Shoten, 1977. (in Japanese).

3) Awaya, K., Nakano, T., Hirata, A. and Hisatomi, S.: Mitosis of immature blood cells found in the circulating blood of rabbits and rats under various conditions. Bull. Yamaguchi Med. Sch., 8: 284, 1961.

4) Awaya, K., Kijima, T. and Takagi, K.: Antigen-induced mitosis in circulating blood lymphocytes. Medicine and Biology, 72: 61-64, 1966. (in Japanese).

5) Awaya, K., Tomonaga, S., Nomura, A. and Kumakura, A.: Phylogeny of the thymus. Acta Anat. Nippon. $44: 132-133$, 1969. (in Japanese).

6) Awaya, K., Kato, S., Yamaguchi, K. and Kan, D.: Review of Iymphocytology. 
Proc. Jpn. Soc. Immunol., 5: 147-149, 1975. (in Japanese).

7) Awaya, K. and Yamaguchi, K.: Bursal lymphocytes (B cells) are smooth-surfaced. J. Clin. Electron Microscopy, 8: 416-417, 1975.

8) Burnet, F.M.: Immunology, aging, and cancer. Medical aspects of mutation and selection. W. H. Freeman and Company, San Francisco., 1976.

9) Cole, G. J. and Morris, B.: The growth and development of lambs thymectomized in utero. Austr. J. Exp. Biol. Med. Sci., 49: 33-53, 1971a.

10) Cole, G. J. and Morris, B.: The cellular and humoral response to antigens in lambs thymectomized in utero. Austr. J. Exp. Biol. Med. Sci., 49: 55-73, 1971 b.

11) Cole, G. J. and Morris, B.: Homograft rejection and hypersensitivity reactions in lambs thymectomized in utero. Austr. J. Exp. Biol. Med. Sci., 49 : 75-88, 1971c.

12) Cole, G.J. and Morris, B.: The normal lymphocyte transfer reaction in lambs thymectomized in utero. Austr. J. Exp. Biol. Med. Sci., 49: 88-99, 1971d.

13) Good, R. A., Finstad, J., Pollara, B. and Gabrielsen, A.E.: Morphologic studies on the evolution of the lymphoid tissues among the lower vertebrates. In: Smith, R. T., Miescher, P.A. and Good, R. A. : Phylogeny of Immunity, pp. 149-170, University of Florida Press, Gainesville, 1966.

14) Hildemann, W.H. and Thoenes, G.H.: Immunological responses of Pacific hagfish. 1. Skin transplantation immunity. Transplantation, 7 : 506-521, 1969.

15) Holbrook, K. A., Perkins, W.D. and Glick, B.: The fine structure of the bursa of Fabricius: "B" cell surface configuration and lymphoepithelial organization as revealed by scanning and transmission electron microscopy. J. Reticuloendothelial Soc., 16: 300-311, 1974.

16) Kojima, M. and Sakuma, H.: Lymphopoiesis in the lymph node. In: Ebashi, S., Yamada, E. and Oda, T., ed. The Cell. Dynamic Function and Fine Structure (Taisha, Suppl.), pp. 2061-2068, Nakayama Shoten, 1977. (in Japanese).
17) Lin, P.S., Cooper, A.G. and Wortis, H.H. : Scanning electron microscopy of human T-cell and B-cell rosettes. New Engl. J. Med., 289 : 548-551, 1973.

18) Linthium, D.S. and Hildemann, W.H. : Immunologic responses of Pacific hagfish. III. Serum antibodies to cellular antigens. J. Immunol., 105 : 912-918, 1970.

19) Marchalonis, J. J. and Cone, R.E.: Biochemical and biological characteristics of lymphocyte surface immunoglobulin. Transplant. Rev., 14 : 3-39, 1973.

20) Matsumura, T.: Ontogeny of the thymolymphatic tissues in man. Saishin-Igaku, 22 : 1898-1909, 1967. (in Japanese).

21) Miller, J.F.A.P.: Immunological function of the thymus. Lancet, $2: 748-749$, 1961.

22) Mori, Y. and Senda, N.: Blast-transformation of normal human peripheral leukocytes in mixed tissue culture. Ann. Rep. Center Adult Dis., 3: 76-83, 1963.

23) Nomura, A.: Ontogeny of the thymolymphatic tissues in the domestic fowls. 2. Histogenesis of thymo-lymphatic tissues. Igaku Kenkyu (Acta Medica), 43: 1-18, 1973. (in Japanese with English summary).

24) Nomura, A., Awaya, K., Kato, S. and Kumakura, A.: Histogenesis of the thymus and the bursa of Fabricius in the domestic fowls. Acta Anat. Nippon., 43 (6, suppl. 1) : 6-7, 1968. (in Japanese).

25) Nowell, P.C.: Phytohemagglutinin: An initiator of mitosis in cultures of normal human leukocytes. Cancer Research, 20 : 462-466, 1960.

26) Polliack, A., Lampen, N., Clarkson, B. D. and De Harven, E.: Identification of human $B$ and $T$ lymphocytes by scanning electron microscopy. J. Exp. Med., 138 : 607-624, 1973.

27) Szenberg, A. and Warner, N. L.: Dissociation of immunological responsiveness in fowls with a hormonally arrested development of lymphoid tissues. Nature. 194 : 146-147, 1962.

28) Thoenes, G.H. and Hildemann, W.H. : Immunological responses of Pacific hagfish. II. Serum antibody production to soluble antigen. In: Developmental Aspects of 
Antibody Formation and Structure (ed. by Sterzel, J. and Riha, I.), pp. 711-726, Academic Press, New York and London, 1970.

29) Tomonaga, S., Hirokane, T. and Awaya, K.: Lymphoid cells in the hagfish. Zool. Mag., 82: 133-135, 1973.

30) Warner, N.L. and Szenberg, A.: Effect of neonatal thymectomy on the immune response in the chicken. Nature, 196: 784-785, 1962.
31) Warner, N.L., Szenberg, A. and Burnet, F.M.: The immunological role of different lymphoid organs in the chicken. I. Dissociation of immunological responsiveness. Austr. J. Exp. Biol., 40: 373387, 1962.

32) Yamaguchi, K. and Awaya, K.: The binding capability of thymic and bursal lymphocytes to Concanavalin A. J. Clin. Electron Microscopy, 9: 627-628, 1976. 


\section{PLATES}




\section{Explanation of Figures}

\section{Plate I}

Figs. 1-4. Electron micrographs of lymphocytes in various tissues of the hagfish, Eptatretus burgeri. Glutaraldehyde and osmium fixation. Uranyl acetate and lead citrate staining.

Fig. 1. Two lymphocytes within the epithelial layer of the gill. $\times 6900$

Fig. 2. Two lymphocytes within the epithelial layer of the intestine. $\times 8600$

Fig. 3. A lymphocyte in peripheral blood. $\times 6000$

Fig. 4. A lymphocyte in the primitive spleen. Sn: sinusoidal space. Gr: granulocyte. $\times 10000$ 



K. Awaya 


\section{Plate II}

Figs. 5-6. Light micrograph of subcutaneously implanted skin grafts on hagfish, Eptatretus burgeri, seven days after grafting. The tissue was fixed in Carnoy solution, embedded in paraffin and stained with hematoxylin and eosin. Ep: Epidermal layer. Bm: Basement membrane of epidermis. Pc: Pigment cell layer in dermis. Hd: Hypodermis.

Fig. 5. Skin autograft with fully surviving epidermis. $\times 250$

Fig. 6. Skin allograft with no epithelial survival. The graft epidermis is completely lost. The outline of the basement membrane persists. $\times 500$ 

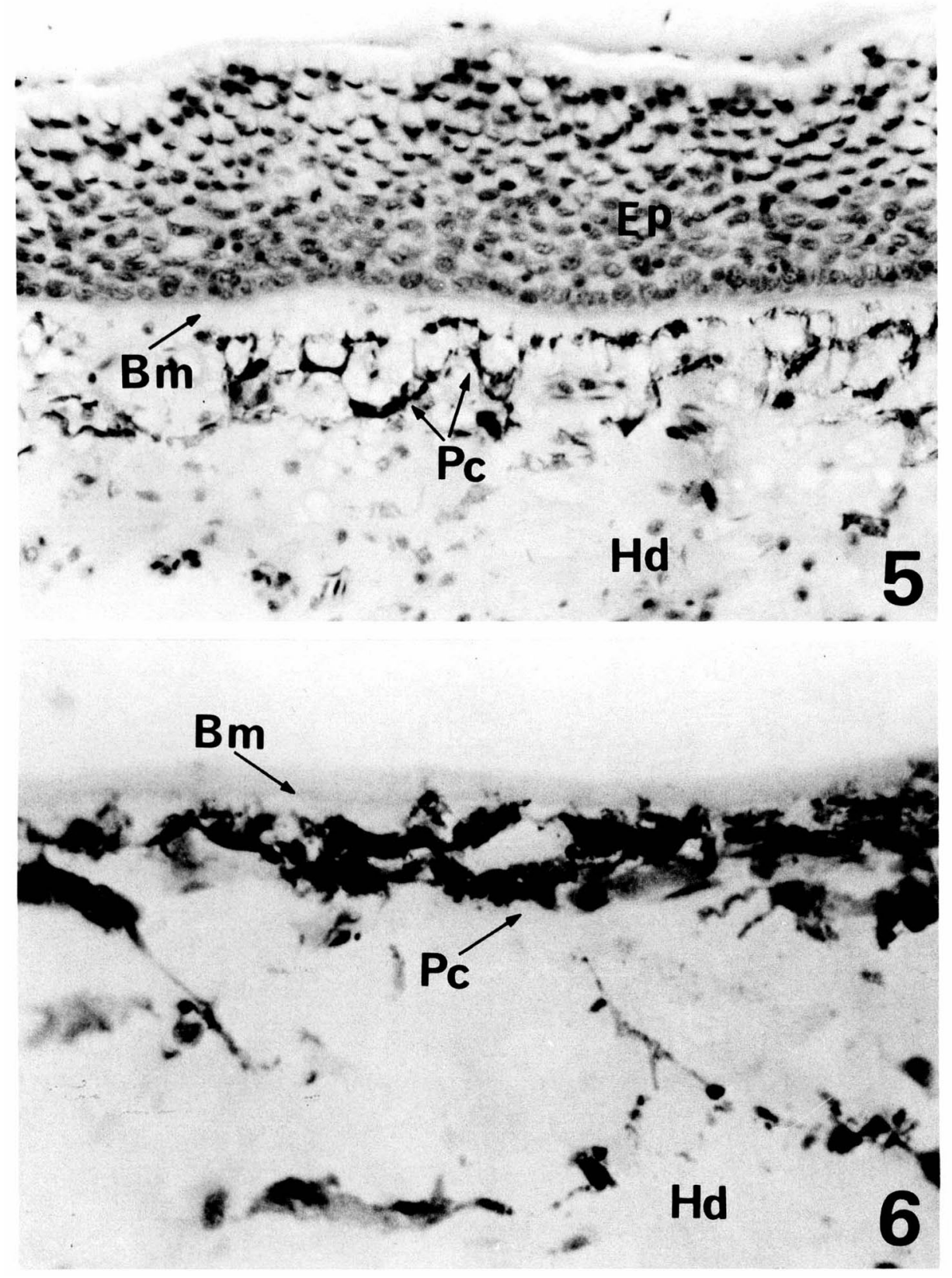


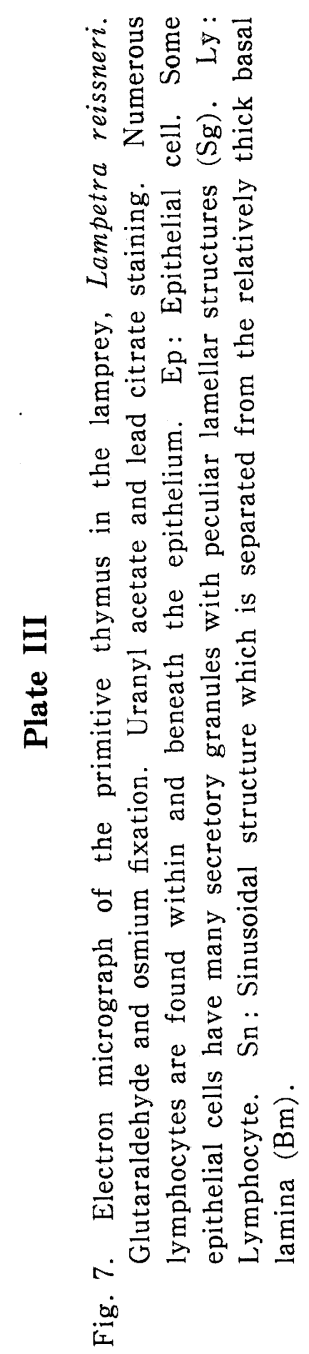


1133

Plate III

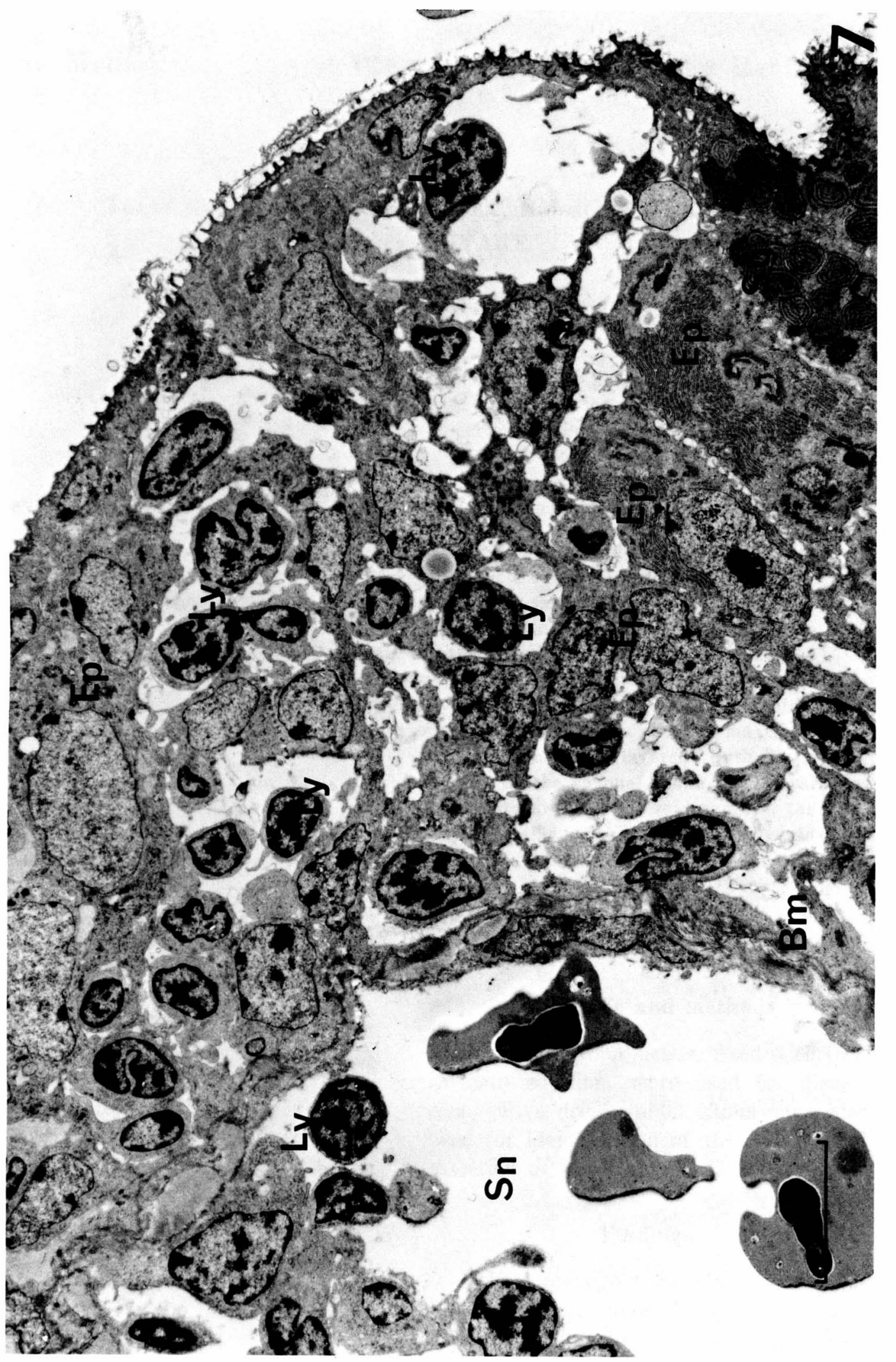

K. Awaya 